\title{
Growth and $\beta$-galactosidase activity in cultures of Kluyveromyces marxianus under increased air pressure
}

\author{
R. Pinheiro, I. Belo and M. Mota \\ Centro de Engenharia Biológica - IBQF, Universidade do Minho, Largo do Paço, Braga Codex, Portugal
}

2003/0044: received 17 January 2003, revised 4 September 2003 and accepted 16 September 2003

\section{ABSTRACT}

R. PINHEIRO, I. BELO AND M. MOTA. 2003.

Aims: To investigate the effect of total air pressure raise on cell growth and intracellular $\beta$-galactosidase activity in batch cultures of Kluyveromyces marxianus CBS 7894.

Methods and Results: A pressurized bioreactor was used for $K$. marxianus batch cultivation under increased air pressure from 1.2 to 6 bar. Under these conditions no inhibition of cell growth was observed. Moreover, the improvement of the oxygen transfer rate (OTR) from the gas to the culture medium by pressurization led to an enhancement of the cell growth rate obtained at atmospheric pressure without aeration. The specific $\beta$-galactosidase productivity increased from 5.8 to $17 \cdot 0 \mathrm{U} \mathrm{gCD}^{-1} \mathrm{~h}^{-1}$ using a 6 -bar air pressure instead of air at atmospheric pressure. The antioxidant enzyme superoxide dismutase (SOD) was slightly induced by the air pressure raise, which indicates that the defensive mechanisms of the cells can cope with an air pressure up to 6 bar.

Conclusions: These experiments showed that the increase of air pressure up to 6 bar is an alternative to other methods of preventing the oxygen limitation and can be applied in the $\beta$-galactosidase production by K. marxianus. Significance and Impact of the Study: The results here reported proved that, in what biological aspects are concerned, it is possible to use the air pressure increase as an optimization parameter of $\beta$-galactosidase production in high-density cell cultures of $K$. marxianus strains.

Keywords: air pressure, $\beta$-galactosidase, Kluyveromyces marxianus.

\section{INTRODUCTION}

The lactose fermenting yeasts Kluyveromyces marxianus, $K$. lactis and $K$. fragilis are important industrial yeasts both in classical applications (biomass, ethanol, enzymes and singlecell protein production) and as hosts for heterologous protein production (Inchaurrondo et al. 1994, 1998; Kiers et al. 1998). Kluyveromyces marxianus offers great advantages, such as good growth yield, acceptability as a safe micro-organism and higher $\beta$-galactosidase activity than other yeasts when lactose is used as substrate (Belem and Lee 1998).

$\beta$-Galactosidase is used as an industrial enzyme in the dairy industry as it allows for the modification or the use of products containing lactose (Dickson and Martin 1980). In

Correspondence to: M. Mota, Centro de Engenharia Biológica-IBQF,

Universidade do Minho, Largo do Paço, 4709 Braga Codex, Portugal

(e-mail:mmota@deb.uminho.pt). addition, $\beta$-galactosidase activity fluctuates or increases continuously over the whole growth phase (Inchaurrondo et al. 1994). The enzyme is continuously synthesized in induced cultures and in batch operations, the maximum yield is obtained at the beginning of the stationary phase of growth, after which the yield of the enzyme decreases (Ranzi et al. 1987). According to some authors (Garcia-Garbay et al. 1987; Barberis and Gentina 1998), the expression of this enzyme is associated with the oxygen transfer rate (OTR) in bioreactors. It is important to establish welldefined and optimized conditions of culture medium oxygenation for yeast growth and $\beta$-galactosidase production. When OTR is limited, growth of aerobic cultures can be enhanced by air pressure raise (Belo and Mota 1998). However, in many cases, increased oxygen partial pressure is toxic to aerobic cultures and inhibits growth and product formation (Onken and Liefke 1989), because of 
the formation of reactive oxygen species (ROS). These ROS, produced as normal by-products of aerobic metabolism, become toxic or lethal by damaging nucleic acids, proteins and membrane lipids. In order to resist to these potentially damaging oxygen species, aerobic organisms have several defence mechanisms among which the antioxidant enzyme superoxide dismutase (SOD) plays an important role (Galiazzo and Labbe-Bois 1993; Gille and Sigler 1995).

In the present work, batch cultures of $K$. marxianus in a pressurized bioreactor were performed in order to obtain a further insight on the influence of moderate total pressure on the yeast growth and $\beta$-galactosidase production. Simultaneously, the induction of the antioxidant enzyme SOD was studied in order to investigate the eventual toxic effect of the increase of oxygen partial pressure. The yeast $K$. marxianus was chosen because it has been extensively used in research and in industrial processes. The strain Kluyveromyces marxianus CBS 7894 exhibits a Kluyver effect for lactose. Several Kluyveromyces strains have been reported to exhibit a 'Kluyver-effect' for lactose - even under oxygen-limited growth conditions, certain disaccharides that support aerobic, respiratory growth, are not fermented (Castrillo et al. 1990).

\section{MATERIALS AND METHODS}

\section{Strain and maintenance}

Kluyveromyces marxianus CBS 7894 was obtained from the Centaalbureau voor Schimmelcultures (Delft, The Netherlands). This strain was stored at $-80^{\circ} \mathrm{C}$ in complex medium with $20 \%$ (v/v) of glycerol. From these stock cultures, agar slants $[2 \%(\mathrm{w} / \mathrm{v})]$ were inoculated and maintained at $4^{\circ} \mathrm{C}$.

\section{Complex medium}

The medium consisted of: $5 \mathrm{~g} \mathrm{KH} \mathrm{KO}_{4}, 1 \cdot 2 \mathrm{~g}\left(\mathrm{NH}_{4}\right)_{2} \mathrm{SO}_{4}$, $0.4 \mathrm{~g} \mathrm{MgSO}_{4} \cdot 7 \mathrm{H}_{2} \mathrm{O}$ and $1 \mathrm{~g}$ yeast extract in $1 \mathrm{l}$ of potassium phosphate buffer $0.2 \mathrm{M}, \mathrm{pH} 5 \cdot 5$. Lactose was used as the main carbon source at $10 \mathrm{~g} \mathrm{l}^{-1}$. After autoclaving $\left(120^{\circ} \mathrm{C}\right.$, $20 \mathrm{~min}$ ), the medium was cooled to room temperature.

\section{Operating conditions}

Yeast cells were pregrown in $250 \mathrm{ml}$ Erlenmeyer flasks filled with $25 \mathrm{ml}$ of the complex medium described above, containing $5 \mathrm{~g}^{-1}$ lactose. Batch cultivations were carried out using a cylindrical stainless steel bioreactor with a total volume of $300 \mathrm{ml}$. The reactor, installed in a shaker bath, was operated with $150 \mathrm{ml}$ of medium, $150 \mathrm{rev} \min ^{-1}$ of shaking rate and $30^{\circ} \mathrm{C}$ of temperature. Air was sparged continuously into the culture medium inside the reactor at $0 \cdot 151 \mathrm{~min}^{-1}$ of aeration rate $(1 \mathrm{vvm})$. The operating pressure was set by the manipulation of the compressed air pressure (inlet gas) and the regulatory valve position in the exit gas line. The reactor was equipped with a pressure transducer to monitor total internal pressure. The values of air pressure studied were: $1 \cdot 2,4 \cdot 0$ and $6 \cdot 0$ bar. A micro-aerated experiment (without forced aeration) was made in an Erlenmyer flask $(250 \mathrm{ml})$ with $150 \mathrm{ml}$ of medium. The flask was placed in an orbital shaker at an agitation speed of $150 \mathrm{rev} \mathrm{min}^{-1}$ under atmospheric pressure (1 bar). This experiment was performed in order to show the effect of a poor oxygenation in the $\beta$-galactosidase production by $K$. marxianus.

\section{Estimation of OTR}

OTR in the pressurized bioreactor and in the Erlenmeyer flask was estimated in blank assays using the sulphite oxidation method (Cooper et al. 1944). This method is based on the oxidation of sodium sulphite $(0 \cdot 2 \mathrm{M})$ to sodium sulphate in the presence of a catalyst, which was, in this case, $\mathrm{Cu}^{2+} 0.001 \mathrm{M}$. In fact, this method measures the rate of $\mathrm{O}_{2}$ absorption by a $\mathrm{Na}_{2} \mathrm{SO}_{3}$ solution. As the chemical reaction is fast enough to ensure that mass transfer is the controlling step, this determination enables to predict the effect of pressure increase on the oxygen mass transfer capacity of the system.

\section{Analytical methods}

At appropriate intervals, culture samples were collected for analysis of cell dry weight, lactose concentration and $\beta$-galactosidase activity. Cell concentration was measured by optical density (O.D.) at $620 \mathrm{~nm}$, and converted to grams of cell dry per litre $\left(\mathrm{gCD}^{-1}\right)$. A calibration curve of O.D. vs gCD $1^{-1}$ was previously drawn. Lactose was determined using the 3,5-dinitrosalycilic acid (DNS) method (Miller 1959).

$\beta$-Galactosidase activity was measured immediately after sampling using $p$-nitrophenyl- $\beta$-D-galactoside (pNPG) as substrate. The enzyme activity determination was performed in phosphate buffer $\left(_{\mathrm{Na}_{2}} \mathrm{HPO}_{4} \quad 3.4 \mathrm{~g} \mathrm{l}^{-1}\right.$; $\mathrm{NaH}_{2} \mathrm{PO}_{4} \cdot \mathrm{H}_{2} \mathrm{O} \quad 2 \cdot 2 \mathrm{~g} \mathrm{l}^{-1}, \mathrm{KCl} 0 \cdot 3 \mathrm{~g} \mathrm{l}^{-1}, \mathrm{MgSO}_{4} \cdot 7 \mathrm{H}_{2} \mathrm{O}$ $0 \cdot 1 \mathrm{~g} \mathrm{l}^{-1}$ and 2-mercaptoethanol $\left.0 \cdot 1 \%(\mathrm{v} / \mathrm{v})\right)$ at $\mathrm{pH} 7 \cdot 0$ and $30^{\circ} \mathrm{C}$. The enzymatic reaction was followed by the absorbance measurement at $405 \mathrm{~nm}$ during $5 \mathrm{~min}$. Activities were calculated by linear regression of the absorbance vs time, $\Delta$ Abs $\min ^{-1}$, using the molar extinction coefficient of pNP, $4.7 \mathrm{mM}^{-1} \mathrm{~cm}^{-1}$. One unit of activity is defined as the amount of enzyme that hydrolyse $1 \cdot 0 \mu \mathrm{mol}$ of $p$-PNG per minute at $\mathrm{pH} 7 \cdot 0$ and $30^{\circ} \mathrm{C}$. Specific $\beta$-galactosidase activity, $\mathrm{U} \mathrm{gCD}^{-1}$, was determined by the ratio between $\mathrm{U} \mathrm{ml}^{-1}$ and gCD $~^{-1}$ for each sample.

The antioxidant enzyme SOD was determined after dialysis of cell extracts using the method of McCord and Fridovich (1969). Protein in cell extracts was measured by 
the coomassie blue method (Bradford 1976) using bovine serum albumin as a standard.

\section{Cell extracts}

Cells were harvested from cultures by centrifugation $(5000 \mathrm{~g}, 10 \mathrm{~min})$, washed once with $50 \mathrm{~mm}$ potassium phosphate buffer ( $\mathrm{pH} 7.8)$ containing $1 \mathrm{mM}$ EDTA and resuspended in the same buffer, frozen and stored at $-20^{\circ} \mathrm{C}$.

Cells were disrupted by shaking them with glass beads $\left(0.5 \mathrm{~mm}\right.$ diameter) for $15 \mathrm{~min}$ at $4^{\circ} \mathrm{C}$ using a bead mill (Vibrogen V14; Edmund Bühler, Bodelshaussen, Germany). All beads and cell debris were removed by centrifugation at $5000 \mathrm{~g}$ for $15 \mathrm{~min}$, at $4^{\circ} \mathrm{C}$. The supernatant was dialysed over night in a 50-mM potassium phosphate buffer $(\mathrm{pH} 7 \cdot 8)$ containing $1 \mathrm{~mm}$ EDTA, at $4^{\circ} \mathrm{C}$. The resulting solution was then used for SOD determination.

\section{RESULTS}

\section{Effect of air pressure on OTR}

For a specific bioreactor and culture medium, OTR enhancement can be achieved by the increase of airflow rate, stirring rate and oxygen solubility in the medium. From Table 1, it is clear that the improvement to OTR by forced aeration and by air pressure rise, which, according with Henry's law, increases the oxygen solubility in the medium.

\section{Dynamics of cell growth}

Time course of growth and lactose consumption of $K$. marxianus are presented in Fig. 1. The exponential growth phase ended after $24 \mathrm{~h}$ of growth for all the experiments carried out with air at increased pressure. The onset of stationary phase coincided with the exhaustion of the lactose from the medium. The increase of pressure from 1.2 to 6 bar caused a slight retardation of cell growth and lactose consumption. In the micro-aerated experiment, cell growth was slower than in the previous experiments and lactose was not totally consumed even after $40 \mathrm{~h}$ of cell growth. The maximum cell concentration obtained in micro-aerated experiment was $2.7 \mathrm{gCD} \mathrm{l}^{-1}$, half of the value obtained at 6 bar air pressure, $5 \cdot 6 \mathrm{gCD} \mathrm{l}^{-1}$.

Table 1 Oxygen transfer rate (OTR) for each experiment made in the pressurized bioreactor and in the flask (micro-aerated)

\begin{tabular}{lllll}
\hline & \multicolumn{4}{l}{ Air pressure (bar) } \\
\cline { 3 - 5 } & Micro-aerated & $1 \cdot 2$ & $4 \cdot 0$ & $6 \cdot 0$ \\
\hline OTR $\left(\mathrm{mgO}_{2} \mathrm{l}^{-1} \mathrm{~h}^{-1}\right)$ & $89 \pm 23$ & $316 \pm 82$ & $806 \pm 89$ & $1099 \pm 65$ \\
\hline
\end{tabular}

Data are mean values $95 \%$ confidence interval.
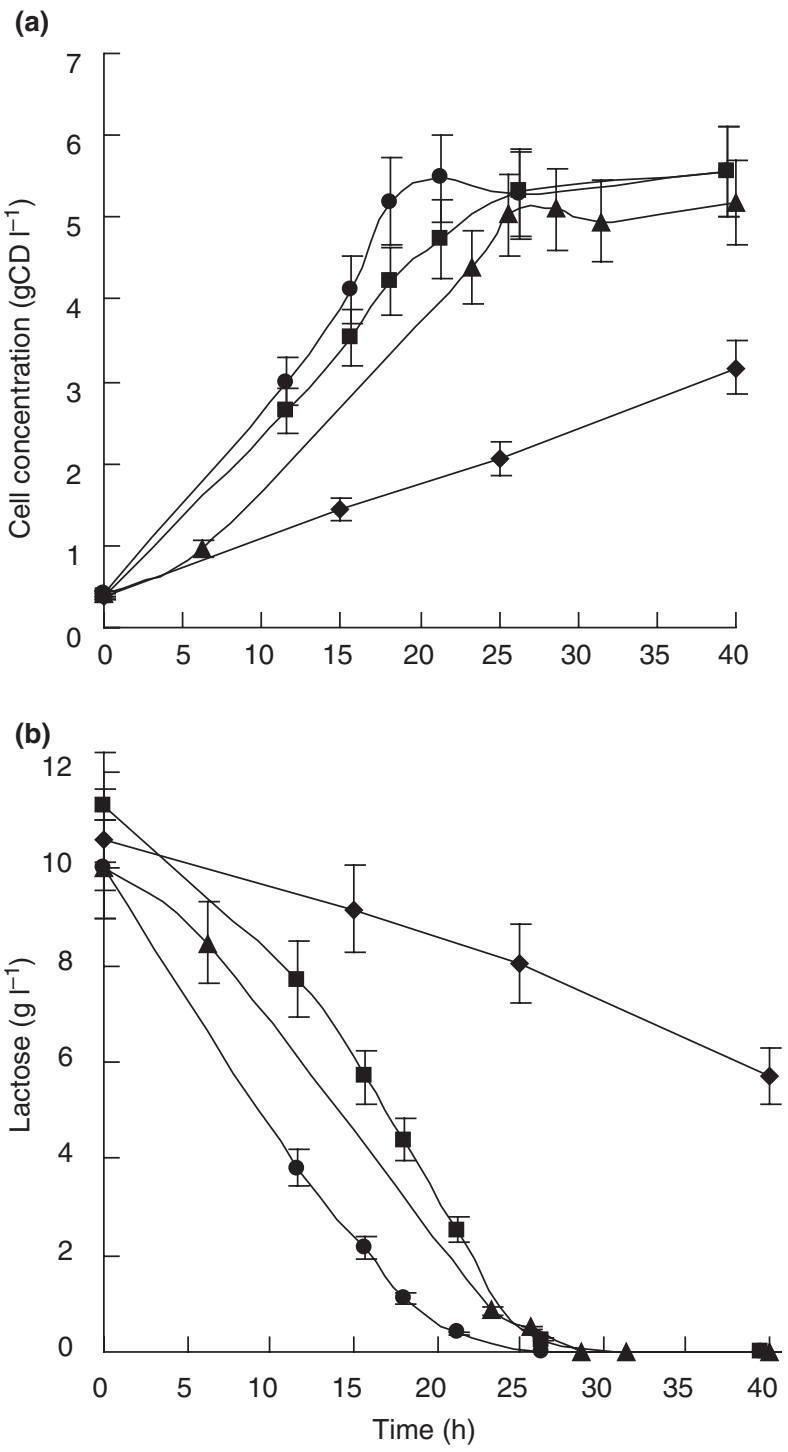

Fig. 1 Cell growth (a) and lactose consumption (b), for Kluyveromyces marxianus during batch experiments made with different pressures: ( 1.2 bar, $(\boldsymbol{\Delta}) 4$ bar and $(\boldsymbol{\square}) 6$ bar air pressure and without pressure, $(\bullet)$ micro-aerated. Data are the mean and standard deviation of independent triplicates

\section{Dynamics of $\beta$-galactosidase formation}

A common feature of $\beta$-galactosidase formation could be observed in all the experiments (Fig. 2). The specific activity remained low (between 130 and $167 \mathrm{UgCD}^{-1}$ ) at the beginning of the cultivation. It then increased reaching a maximum at the early stationary phase, in the range of $265-381 \mathrm{U} \mathrm{gCD}^{-1}$. The maximum specific activity was attained for the highest air pressure studied (6 bar), $380.9 \mathrm{U} \mathrm{gCD}^{-1}$. Results presented by Inchaurrondo et al. (1994) showed that after the onset of the stationary phase, 


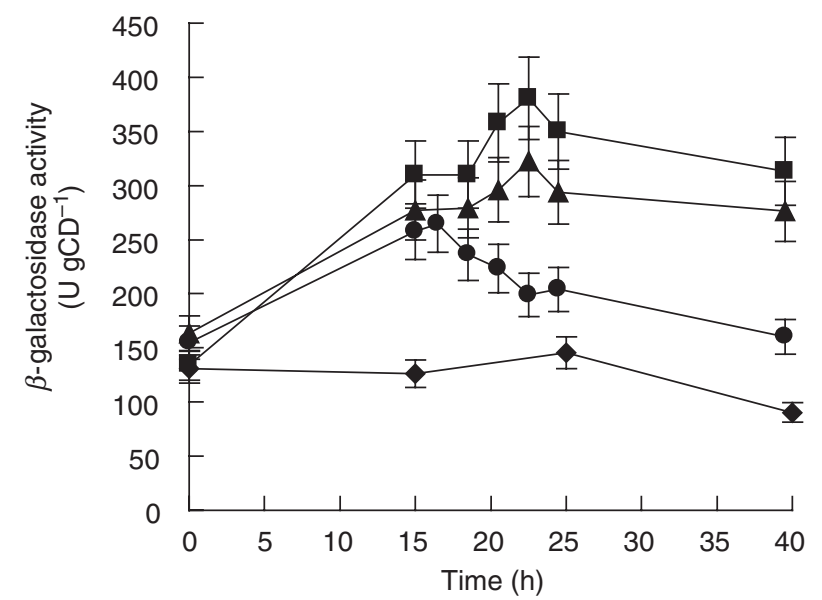

Fig. $2 \beta$-Galactosidase specific activity of Kluyveromyces marxianus during batch experiments made with: $(\boldsymbol{O}) 1 \cdot 2$ bar, $(\boldsymbol{\Delta}) 4$ bar and (ם) 6 bar air pressure and $(\diamond)$ micro-aerated, without air sparging. Data are the mean and standard deviation of independent triplicates

$\beta$-galactosidase activity remained stable till the end of the experiment, after reaching its maximum activity. However, in the present case, for the experiments in the pressurized bioreactor, the enzyme activity showed a slight decrease after reaching its maximum activity level. Similar results were presented in the work of Ranzi et al. (1987). These authors found that $\beta$-galactosidase activity increased during the exponential growth phase reaching a maximum at the early stationary phase. After that it decreased continuously throughout the stationary growth phase. In the present work, the highest rate of activity loss was observed at 1.2 bar air pressure.

Figure 3 shows the effect of OTR increase on the specific $\beta$-galactosidase productivity (calculated with the maximum value attained for each experiment). The OTR improvement was followed by an increase in $\beta$-galactosidase productivity (Fig. 3). As expected, the specific $\beta$-galactosidase productivity had a $2 \cdot 5$-fold increase by forced aeration introduction into the culture medium, at slightly increased air pressure ( 1.2 bar) compared with the experiment without aeration. This increase was even higher, 3.0-fold, at 6 bar air pressure, corresponding to an OTR of $1099 \mathrm{mgO}_{2} \mathrm{l}^{-1} \mathrm{~h}^{-1}$.

\section{SOD activity}

The antioxidant enzyme SOD was studied in order to investigate the influence of air pressure raise on the antioxidant response of yeast cell. The increase in OTR from $316 \mathrm{mgO}_{2} \mathrm{l}^{-1} \mathrm{~h}^{-1}(1.2 \mathrm{bar})$ to $1099 \mathrm{mgO}_{2} \mathrm{l}^{-1} \mathrm{~h}^{-1}$ (6 bar) induced the activity of this antioxidant enzyme. The total SOD activity had a slight increase from $36 \cdot 6$ to $65.1 \mathrm{U} \mathrm{mg}$ protein ${ }^{-1}$, after $24 \mathrm{~h}$ of cell exposure to 1.2 and 6 bar air pressure, respectively. This shows the ability of

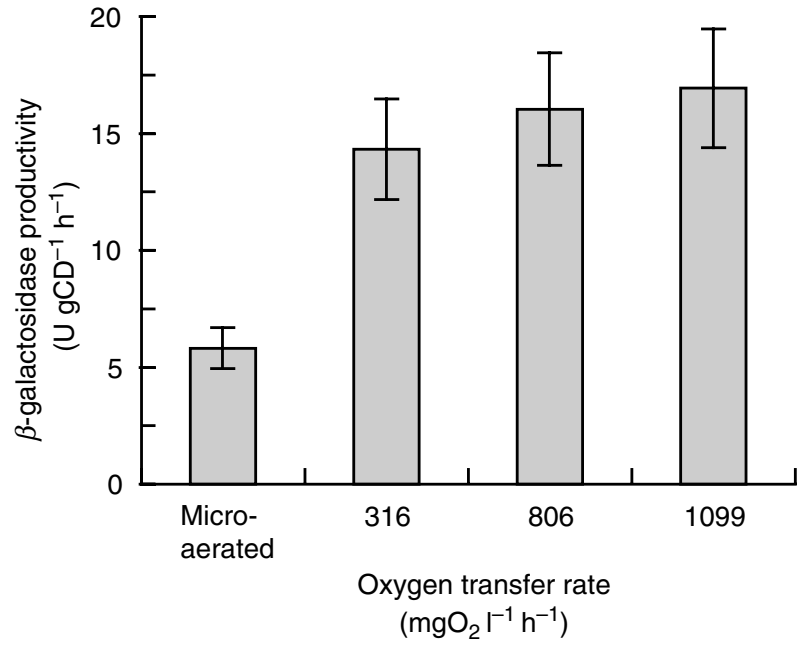

Fig. 3 Effect of oxygen transfer rate on the specific $\beta$-galactosidase specific productivity in cultures of Kluyveromyces marxianus during batch growth. $\beta$-Galactosidase specific productivity was determined by the ratio between the maximum $\beta$-galactosidase specific activity obtained in each experiment and the time that value was obtained. Data are the mean and standard deviation of independent triplicates

$K$. marxianus cells to respond to the increase of ROS formation because of hyperoxygenation.

\section{DISCUSSION}

The results presented are consistent with those reported in a previous work, by Pinheiro et al. (2000), where the pressure increase had no negative effects on cell metabolism. However, the total pressure effects on $\beta$-galactosidase production were not analysed.

Several authors (Garcia-Garbay et al. 1987; Barberis and Gentina 1998) reported the great importance of forced aeration into the culture medium for cell growth and $\beta$-galactosidase production. This was also found in the present work, as significant differences were obtained for cell growth and $\beta$-galactosidase activity, when cells were cultivated without aeration (flask) and with aeration at slightly increased pressure ( 1.2 bar).

Despite the OTR increase of threefold, because of the air pressure raise from $1 \cdot 2$ to 6 bar, no significant difference on cell growth was observed. Probably, the highest OTR value used was excessive for the low-cell density present in the culture and the cells did not use all the available dissolved oxygen in the culture medium. Although no improvement in cell mass production was obtained, no inhibitory effects on cell activity were observed at high air pressure. Regardless the inexistence of an oxygen probe in the pressurized bioreactor, high dissolved oxygen concentration in the culture medium was predicted for the experiments at the highest value of air pressure, 6 bar. As a consequence of 
the higher oxygen concentration, the cells may retard or stop their growth, depending on their sensitivity to oxygen (Onken and Liefke 1989). In this work, the SOD induction showed the cell sensitivity to high oxygen concentrations. However, as no cell growth inhibition was observed under pressurized conditions, it is safe to say that the cells of the strain used can cope with air pressure values up to 6 bar.

For all the experiments made with air pressure the $\beta$-galactosidase activity decreased after reaching its maximum value. The reduction of $\beta$-galactosidase activity after $22 \mathrm{~h}$ leads to the conclusion that the operation should be stopped immediately after the stationary phase has been reached. Inchaurrondo et al. (1994) observed, under optimal conditions for different Kluyveromyces strains, a 1·3-1·8-fold increase of $\beta$-galactosidase activity during the brief deceleration phase. Ranzi et al. (1987) found a fivefold increase of the specific $\beta$-galactosidase activity, from the early exponential growth phase to the early stationary phase, when a $K$. lactis CBS 2360 was grown in batch cultures of lactose. Similar results were reported in K. marxianus (Mahoney et al. 1975) and K. lactis (Holmberg et al. 1984).

In the present work a maximum value of 16.9 $\mathrm{UgCD}^{-1} \mathrm{~h}^{-1}$ was achieved at 6 bar air pressure.

Although the low cell concentration used in this work, the effects of increase air pressure are expected for higher cell concentrations. Thus, in what biological aspects are concered, it is possible to use the air pressure raise up to $6 \mathrm{bar}$, as an optimization parameter of $\beta$-galactosidase production in high-density cell cultures where oxygen is a limiting factor. Obviously, a high yield strain should be used in the production of the enzyme $\beta$-galactosidase, which was not the case of the present work. Nevertheless, similar behaviour under increased air pressure is anticipated for other Kluyveromyces strains. However, new studies should be performed whenever a different microbial strain is used, mainly in the case of genetically modified strains (Belo and Mota 1998).

\section{ACKNOWLEDGEMENTS}

This work was supported by a PhD grant from PRAXIS XXI (Portugal).

\section{REFERENCES}

Barberis, S. and Gentina, J.C. (1998) Effect of dissolved oxygen level on lactase production by Kluyveromyces fragilis. Fournal of Chemical Technology and Biotechnology 73, 71-73.

Belem, M.A.F. and Lee, B.H. (1998) Production of bioingredients from Kluyveromyces marxianus grown on whey: an alternative. Critical Reviems in Food Science and Nutrition 38, 565-598.

Belo, I. and Mota, M. (1998) Batch and fed-batch cultures of E. coli TB1 at different oxygen transfer rates: effect of stirring and oxygen partial pressures on cell growth and cytochrome b5 production. Bioprocess Engineering 18, 451-455.

Bradford, M.M. (1976) A rapid and sensitive method for the quantification of microgram quantities of protein using the principle of protein-dye binding. Analytical Biochemistry 72, 248-255.

Castrillo, J.I., Kaliterna, J., Weusthuis, R.A., van Dijken, J.P. and Pronk, J.T. (1990) High-cell-density cultivations of yeasts on disaccharides in oxygen limited batch cultures. Biotechnology and Bioengineering 49, 621-628.

Cooper, C.M., Fernstrom, G.A. and Miller, S.A. (1944) Performance of agitated gas-liquid contacters. Industrial and Engineering Chemistry 36, 504-509.

Dickson, R.C. and Martin, J.S. (1980) Physiological studies of $\beta$-galactosidase induction in K. lactis. Fournal of Bacteriology 142, 777-785.

Galiazzo, F. and Labbe-Bois, R. (1993) Regulation of CuZn and Mn-superoxide dismutase transcription in Saccharomyces cerevisiae. FEBS 315, 197-200.

Garcia-Garbay, M., Torres, J., López_munguía-Canales, A. and Casas, L.T. (1987) Influence of oxygen transfer rate on $\beta$-galactosidase production from Kluyveromyces marxianus. Biotechnology Letters, 9, 417-420.

Gille, G. and Sigler, K. (1995) Oxidative stress and living cells. Folia Microbiologia 40, 131-152.

Holmberg, A., Oy, R., Ojama, H., Perttula, M. and Ranta, J. (1984) Utilization of models in the prediction and optimization of yeast beta-galactosidase production. In Third European Congress of Biotechnology, vol. I. pp. 699-704. Weinheim: Verlag Chemie.

Inchaurrondo, V.A., Flores, M.V. and Voget, C.E. (1994) Yeast growth and $\beta$-galactosidase production during aerobic batch cultures in lactose-limited synthetic medium. Proceedings in Biochemistry 29, 47-54.

Inchaurrondo, V.A., Flores, M.V. and Voget, C.E. (1998) Growth and $\beta$-galactosidase synthesis in aerobic chemostat cultures of Kluyveromyces lactis. Fournal of Industrial Microbiology and Biotechnology 20, 291-298.

Kiers, J., Zeeman, A.M., Luttik, M., Thiele, C., Castrillo, J.I., Steensma, H.Y., van Dijken, J.P. and Pronk, J.T. (1998) Regulation of alcoholic fermentation in batch and chemostat cultures of Kluyveromyces lactis CBS 23359. Yeast 14, 459-469.

McCord, J.M. and Fridovich, I. (1969) Superoxide dismutase: an enzymatic function for erythrocuprein (hemocuprein). Fournal of Biological Chemistry 244, 6049-6050.

Mahoney, R., Nickerson, T. and Whitaker, J. (1975) Selection of strains, growth conditions and extraction procedures for optimum production of lactase from Kluyveromyces fragilis. Fournal of Dairy Science 58, 1620-1629.

Miller, G.L. (1959) Use of dinitrosalycilic acid reagent for determination of reducing sugar. Analytical Chemistry 31, 426-428.

Onken, U. and Liefke, E. (1989) Effect of total and partial pressure (oxygen and carbon dioxide) on aerobic microbial processes. Advances in Biochemistry, Engineering and Biotechnology 40, 137-169.

Pinheiro, R., Belo, I. and Mota, M. (2000) Air pressure effects on biomass yield of two different Kluyveromyces strains. Enzyme and Microbial Technology 26, 756-762.

Ranzi, B.M., Porro, D., Compagno, C. and Martegani, E. (1987) Protein and cell volume distributions during the production of betagalactosidase in batch cultures of Kluyveromyces lactis. Fournal Biotechnology 5, 227-231. 